\title{
Syntactic Priming Effects between Modalities: A Study of Indirect Questions/Requests among Persian English Learners
}

\author{
Reza Biria \\ Department of English, Islamic Azad University - Khorasgan Branch, Isfahan, Iran \\ Ahmad Ameri-Golestan (Corresponding author) \\ Department of English, Islamic Azad University - Khorasgan Branch, Isfahan, Iran \\ E-mail: a.ameri@khuisf.ac.ir \\ Inés Antón-Méndez \\ E-mail: iantonme@une.edu.au
}

\begin{abstract}
This study examines the impact of syntactic priming on production of indirect questions/requests by Persian learners of English as a foreign language. Eighty learners participated in two experiments investigating the impact of syntactic priming on oral production and the possibility of transfer of the priming effects to a different modality. Production Experiment showed that priming resulted in increased production of the target structure by the Experimental groups as compared with production by the Control groups. Transfer Experiment showed that the rate of production of the target structure remained significantly higher for participants in the Experimental groups.
\end{abstract}

Keywords: Syntactic priming, Language production, Modality transfer

\section{Introduction}

Syntactic priming refers to a tendency to produce or repeat a recently produced or heard structure $($ Bock, 1986) that is, the phenomenon by which processing of an utterance is facilitated by processing of another one which shares the same underlying syntactic structure. This facilitation can help understand the nature of syntactic representation (Branigan, 2007). After the discovery of syntactic priming (also called structural persistence and structural priming) over 20 years ago, there have been numerous studies across a wide variety of populations. Syntactic priming has been the focus of studies with children (e.g., Garrod \& Clark, 1993; Fisher, 2002; Tomasello, 2000), aphasiacs (e.g., Saffran \& Martin, 1997), bilinguals (e.g., Bernolet, Hartsuiker, \& Pickering, 2007; Schoonbaert, Hartsuiker, \& Pickering, 2007), and second/foreign language learners (e.g., Gries \& Wulff, 2005; Kim \& McDonough, 2008; McDonough, 2006).

Bock (1986) reported the first study which specifically used structural priming to investigate the processing and representation of language structures. In her study, speakers repeated prime sentences (transitive and dative structures) and afterwards described target pictures which were semantically unrelated to the prime sentences. The results showed that speakers tended to use an active description of the target picture after an active prime structure and a passive description after a passive prime structure. The same effect was observed with dative sentences. Pickering and Ferreira (2008) pointed out that the results of Bock's (1986) study reveal that priming happens automatically and is not related to specific communication purposes or prime-target relationships (Levelt \& Kelter, 1982), or discourse factors such as register (Weiner \& Labov, 1983).

Bock's (1986) initial finding encouraged several researchers to investigate the nature of the phenomenon and its linguistic implications more in depth. Branigan, Pickering, Liversedge, Stewart, and Urbach (1995) concluded that syntactic priming can occur within production, within comprehension, and between comprehension and production. Within production, uttering particular syntactic forms might affect the production of subsequent utterances. For example, if a prime is produced that contains a double-object structure (The rock star sold an undercover agent some cocaine), it increases the probability of participants producing a target with the same structure (The girl handed the man a paintbrush); and the same will happen with alternative structures such as prepositional objects. Within comprehension, Branigan et al. found priming with locally ambiguous sentences. For example, readers process an "early closure" sentence (While the woman was eating the creamy soup went 
cold) faster if it is encountered after another "early closure" sentence, and a "late closure" sentence (While the woman was eating the creamy soup the pudding went cold) is read faster immediately after reading another "late closure" sentence (Branigan et al.). With regard to the "comprehension-to-production" priming, Branigan et al. also found produced sentences are often structurally similar to recently heard utterances. For example, when shopkeepers were asked At what time does your shop close?, they answered At five o'clock more frequently than Five o'clock, while the question What time does your shop close? was followed by Five o'clock more often than At five o'clock. They pointed out that a process which is common to both comprehension and production might be the source of priming, although the nature of that source is unclear.

Pickering and Ferreira (2008) reviewed several studies which used syntactic priming and concluded that they provide evidence for autonomous syntax. They argued that the production of a sentence depends largely on an abstract syntactic form which can be defined in terms of parts of speech and phrasal constituents and they believe that it is this abstract syntactic structure that influences syntactic priming.

Other studies have addressed the question of durability of syntactic priming. These studies have dealt with the question of whether priming is long lasting and results in implicit learning, or decays over time (Bock \& Griffin, 2000; Branigan et al., 1999). Seger (1994) defined implicit learning as involving knowledge which is not accessible to consciousness; it is characterized by being, to some extent, complex and abstract; it happens incidentally as some tasks are being performed, and finally, it is preserved in cases of amnesia (Bock \& Griffin, 2000). Bock and Griffin (2000) believed that these four characteristics can be attributed to syntactic priming as well.

Research on syntactic priming (both in a first and second language, L1 and L2 respectively) during the last two decades has focused mainly on the participants' performance when there is a choice between alternative constructions; such as the choice between prepositional-object and double-object (Chang, Dell, Bock, \& Griffin, 2000), or the choice between active and passive sentences (Bock \& Griffin 2000).

\section{Indirect questions/requests in Persian}

Here, however, we focus on a single type of structure: indirect questions/requests in the production of Persian-speaking learners of English as a foreign language (EFL). Persian-speaking EFL learners' production of indirect questions/requests seems to be greatly affected by their first language which has a quite different structure from English. What follows is a simple exemplification of indirect questions/requests in Persian. Consider the following situation. Someone asks a friend to do something for him and now that person is reporting the request. The original request is:

Example 1:

1. Mitooni mashineto biyari

Can you bour car bring

Can you bring your car?

This request is reported indirectly as either (a) or (b) in English:

1. a. He asked me to bring my car.

1. b. He asked me if I could bring my car.

And directly as:

1. c. He asked me "can you bring your car?"

Persian speakers, however, employ two different types of sentences when reporting this request in Persian:

$\begin{array}{rrrrr}\text { 1.d. Be } & \text { man } & \text { goft } & \text { mashineto } & \text { biyar. } \\ \text { To } & \text { me } & \text { told } & \text { yourcar } & \text { bring }\end{array}$

He told me you bring your car.

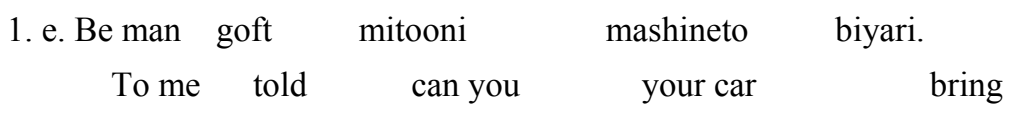

He told me can you bring your car.

As the example shows, in Persian, it is more common to use direct reporting when referring to someone else's speech.

As well as looking at the possible effect of syntactic priming on the subsequent production of a particular structure, it is of interest to consider whether the effects would transfer from one modality or skill (speaking) to 
another (writing), since the assumption that syntactic priming leads to learning would imply processing changes that are modality neutral.

In sum, the research questions of the present study can be formulated as follows:

1. Does exposure to indirect questions/requests in L2 increase the likelihood of subsequently producing these structures in L2?

2. Does syntactic priming in the oral contexts encourage the renewed use of indirect questions/requests in upcoming written production?

\section{The Pilot Study}

In order to see what kind of structures Persian speakers use when they are reporting a question or request, a questionnaire in the form of a preference test, was given to thirty Persian native speakers. These participants were different from those participating in the two experiments reported below. The questionnaire contained 40 sentence triads in Persian and participants were asked to mark the sentence they preferred from among the set of three alternatives. The following are two examples of the test items.

Example 2:

2. a. Milad

Milad

$$
\text { az doostesh }
$$

khast

from his friend

asked

mitooni

mashinet-o

biari?

Milad asked his friend can you bring your car.

2. b. Milad az doostesh khast ke mitooneh mashinesh-o biareh

Milad from his friend asked that can he his

bring

Milad asked his friend if he can bring his car.

2. c. Milad az doostesh

biar

Milad from his friend asked that you your car bring

Milad asked his friend that you bring your car.

Example 3:

$\begin{array}{rlrr}\text { 3. a. Mina } & \text { dirooz } & \text { ketab-ra } & \text { kharid } \\ \text { Mina } & \text { yesterday } & \text { book-OM } & \text { bought }\end{array}$

Mina bought the book yesterday.

3. b.!Mina dirooz kharid ketab-ra

Mina yesterday book-OM bought

Mina bought the book yesterday.

3. c. *Dirooz ketab-ra kharid Mina

Yesterday book-OM bought Mina

Mina bought the book yesterday.

There were 20 sentence triads which contained a request (such as Example 2 above), and 20 fillers (such as Example 3 above) where participants had to choose between different word orders, considering the fact that Persian is an SOV language which also lets OSV and even SVO (Lotfi, 2003).

This study was conducted before the main experiments (Production Experiment and Transfer Experiment) in order to see whether Persian speakers favor direct or indirect speech when they are reporting a request or question. The results showed that participants, when asked to report a request, such as "Can you bring your car?" preferred direct reporting, such as in "He asked his friend can you bring your car?" 78 percent of the time and indirect reporting, such as in "He asked his friend that you bring your car" 22 percent of the time.

\section{Production Experiment}

We conducted production experiment in order to answer the first research question, that is, whether hearing indirect questions/requests in L2 increases the likelihood of subsequently producing these structures in the second language. 


\subsection{Method}

\subsubsection{Participants}

Participants of the study were 80 Persian speaking L2 learners of English who were studying English at Gooyesh Language Institute and Khorasgan Azad University in Isfahan. These participants were selected from among a larger 135-participant sample after taking Allen's (1992) proficiency test. In order to group participants, the following procedure was followed. The 40 participants who got the highest proficiency scores were placed in the High-proficiency groups, that is, those participants who scored 161-144 (out of 200 which is the maximum possible score in the placement test). In order to eliminate the Low-proficiency participants, the 40 participants who got the lowest scores (less than 101) were excluded. Of the remaining 55 participants, the forty who were in the middle of the list were placed in the Mid-proficiency groups, that is, those participants who scored 119-101. This was done in order to make sure that the High-proficiency and Mid-proficiency groups were significantly different from each other. The same participants took part in both experiments described below.

Participants of the study were, then, placed in four groups with respect to proficiency and treatment, namely Experimental High-proficiency, Experimental Mid-proficiency, Control High-proficiency, and Control Mid-proficiency ( $\mathrm{N}=20$ in each group). No low-proficiency group was assigned, because such participants would not have been able to perform the task. The groups labeled Experimental were those that were subject to syntactic priming, while the Control groups provided the baseline.

In order to ensure the comparability of the Experimental and Control groups, two independent samples t-tests were conducted comparing proficiency scores. The results of the t-test comparing the Experimental High-proficiency $(M=150.96, S D=5.91)$ and Control High-proficiency $(M=153.40, S D=4.90)$ showed no significant difference in proficiency, $t(38)=1.43, p=.16$. The results of the t-test comparing the Experimental Mid-proficiency $(M=110.45, S D=5.58)$ and Control Mid-proficiency $(M=109.25, S D=6.09)$ also showed no significant difference in proficiency scores, $t(38)=0.65, p=.52$.

\subsubsection{Materials}

There were two sets of 45 pictures, one set for the researcher and one for the participants. The critical or experimental pictures $(\mathrm{N}=20)$ depicted a scene where somebody was seen to be asking or requesting something from somebody else. This question or request was made apparent by means of a balloon so that participants knew they were supposed to report this question/request. For example, someone is asking to talk with the manager, or someone is asking a friend to explain how a cell-phone works, etc. See Figure 1 for an example of the experimental pictures.

All participants saw the same set of pictures, but the researcher's set was different for the Control and Experimental groups. The researcher's pictures for the Experimental groups provided the researcher with the opportunity to produce a prime, that is, the researcher also had pictures where there was a question or request that had to be reported. For the Control group, the researcher described a picture that did not require direct reporting and therefore lacked a priming sentence.

In addition to the experimental pictures, there were 25 filler pictures that served to hide the purpose of the study. Like the experimental pictures, the fillers depicted a scene where people were seen to be involved in some sort of conversation. For example, a police officer is giving directions to people, or while someone is watering the flowers another person is talking about the weather and the flowers. Similarly, the sentences used in conversations in both the experimental and filler pictures were made apparent by means of balloons. For example, in the picture in Figure 2 a young man is watering the trees and flowers and another friend is talking about how beautiful the flowers are. When describing this filler, the researcher would say: "Here, there are two young men in a yard. One of them is watering the flowers and the other is also talking about the trees and the flowers."

For the filler pictures and unlike the experimental ones, the researcher would not report the sentence in the balloon; however, participants had been asked to describe the picture and always report the sentence in the balloon.

\subsubsection{Procedure}

Participants met with the researcher in individually held sessions. The experiment took place in a quiet room and participants were given enough time in order to describe the pictures. Each session lasted between 45 and 60 minutes. First, the researcher explained the procedure to participants and after he had made sure that participants were familiar with the procedure, the experiment started. In order to make sure that participants became completely familiar with picture description, some trial pictures were described before the main part of the 
experiment started. Furthermore, in order to hide the purpose of the research, the researcher mentioned that he was interested in the type of sentences that people would use to describe a variety of situations.

First, the researcher described a picture and, after he was done with his description, the participant had to look through their set of pictures and choose the one he thought best matched the situation just described by the researcher and describe it. For example, if the researcher described a picture in which a student is asking the teacher to explain a point, the participant could choose a picture of a store where a man is asking his friend to explain how a cell phone works.

The researcher and participants would continue in this way until they had described all the pictures (both experimental and filler). The experimental and filler pictures were mixed in a semi-random arrangement, making sure that no two experimental or even similar structures were placed one after the other.

For the critical pictures, the researcher either described the pictures including an instance of indirect request/reporting (with the Experimental groups), or described the picture but did not produce any instance of direct or indirect request/reporting (with the Control groups). For example, for the Experimental group, the researcher would say: "Here we have a class. All the students are gone, but one of the students is talking with the teacher. She is asking if he can explain a grammatical point to her." For the Control group, on the other hand, the researcher would say: "Here we have a class and all the students are gone, but it seems that one of the students wants to talk with the teacher and needs some help with a grammatical problem." It should be emphasized that all participants' pictures had a balloon containing the sentence the interlocutors were uttering which participants were instructed to report.

\subsubsection{Scoring}

In order to facilitate the scoring procedure, a checklist was prepared. The experimental prime sentences were of three types: Wh-questions/requests (Where is the restaurant?), requests/questions with auxiliaries or yes/no questions (Could you mail these letters for me?), and requests in the form of imperatives (Take a seat, please; or Call us when you arrive). When participants produced the same structure as the prime in their description, the sentence was scored, that is, it was coded as "Indirect questions/requests." These were sentences which were indirect wh-questions, yes/no questions, or infinitive clauses that contained verbs like ask, request, require, invite, want to know, wonder, etc. Other types of responses were coded as "Other" and not scored. For example, the researcher presented the following prime:

The student is asking the teacher if he can explain a grammatical point.

The following target sentence would be considered acceptable:

The man is asking his friend if/whether he can explain how the cell-phone works.

For each participant, a mean score was obtained for the whole session which was the sum of all the instances in which they had described a picture using the target structure. The maximum possible score was 20.

\subsection{Results}

The means for the groups were $14.70(S D=2.36), 13.20(S D=2.70), 4.80(S D=2.07)$, and $3.95(S D=2.28)$ for the Experimental High-proficiency, Experimental Mid-proficiency, Control High-proficiency, and Control-mid proficiency, respectively.

To address the first research question, which asked about the occurrence of syntactic priming in L2, the data were analyzed using a $2 \times 2$ analysis of variance with score as the dependent variable and group (Experimental and Control) and proficiency (High and Mid) as independent variables. There was a statistically significant main effect of group $F(1,76)=327.47, p<.01$ with Experimental groups being associated with significantly higher scores $(M=13.95, S D=2.62)$ than Control groups $(M=4.37, S D=2.19)$. Furthermore, a significant main effect was found for proficiency, $F(1,76)=4.93, p<.05$, indicating that more proficient participants had significantly higher scores $(M=9.75, S D=5.47)$ than did less proficient ones $(M=8.57, S D=5.29)$. The interaction between group and proficiency, however, was not statistically significant, $F(1,76)=0.377, p=.54$.

In sum, the Persian-speaking EFL learners who participated in this study produced more indirect questions/requests when primed for this structure. The results provide the answer to the first research question regarding whether priming results in increased production of indirect questions/requests.

\section{Transfer experiment}

This experiment was intended to investigate whether participants of the study could transfer priming effects from one modality or skill (speaking) to another (writing). 


\subsection{Method}

\subsubsection{Participants}

The same participants (except one who voluntarily decided not to take part in this experiment) who took part in the previous experiment also participated in the transfer experiment.

\subsubsection{Materials}

Materials consisted of a completely new set of 45 pictures of similar characteristics as those used in the previous experiment. For this experiment, however, the pictures were printed in a booklet and participants were asked to provide the description in writing. Furthermore, in transfer experiment there was no researcher's set.

\subsubsection{Procedure}

All participants were asked to participate in this experiment immediately after the first experiment. The researcher provided participants with the booklet as well as the instructions on how to complete it, that is, they were supposed to provide the description of the pictures in writing. After the researcher made sure that participants were familiar with the procedure, participants were asked to complete the booklet. To help participants with picture description, a sample filler picture had been described.

\subsubsection{Scoring}

Sentences were coded as "Indirect questions/requests" or "Other" following the same criteria as for production experiment.

\subsection{Results}

The means for the groups were $13.75(S D=2.75), 11.90(S D=3.01), 4.10(S D=2.12)$, and $3.89(S D=2.42)$ for the Experimental High-proficiency, Experimental Mid-proficiency, Control High-proficiency, and Control-mid proficiency, respectively.

The data were subjected to a $2 \times 2$ analysis of variance with score as the dependent variable and group (Experimental and Control) and proficiency (High and Mid) as fixed factors. There was a statistically significant main effect of group $F(1,75)=227.50, p<.01$. Experimental groups had significantly higher proportion of target structures $(M=12.83, S D=2.99)$ than did Control groups $(M=4.00, S D=2.25)$, which meant the benefit accrued on spoken production due to syntactic priming was observable in the domain of written production. No significant main effect was obtained for proficiency, $F(1,75)=3.08, p=.08$, indicating that there was no significant difference between more proficient participants $(M=8.92, S D=5.45)$ and less proficient ones $(M=$ $8.00, S D=4.87)$. Furthermore, no significant interaction effect was obtained for group and proficiency, $F(1,75)$ $=1.98, p=.16$.

\section{Discussion: Research questions revisited}

Syntactic priming phenomena have been investigated from very different perspectives in the psycholinguistic literature on both first and second language acquisition. In addition to language production, syntactic priming has been researched with respect to issues such as first and second language comprehension, language processing, the mental representation of language among native speakers, bilinguals, and second language learners, and last but not least the impact of syntactic priming on retention or learning. In this study, we wanted to examine whether syntactic priming would be found in a second language and whether it would transfer from one modality (speaking) to another (writing) taking into account a particular target structure (indirect questions/requests) that had not been investigated until now. Based on personal and classroom observation, this structure seems to be underrepresented in the production of Persian learners of English and can therefore be an ideal candidate to test the potential benefits of syntactic priming in $\mathrm{L} 2$ acquisition.

We posed two research questions. The first research question asked about the impact of syntactic priming on the production of the target structure, namely indirect questions/requests, among Persian speaking L2 learners of English. The results obtained from the first experiment (production experiment) showed that those participants who had been primed for the target structure did produce more of the target structure than those who had not. This indicates that priming was effective even though it was conducted in a second language and even though it concerned a structure apparently difficult for the learners, judging by the low production of the Control group.

These results support previous research on syntactic priming among second/foreign language learners, especially Kim and McDonough (2008) who showed the impact of syntactic priming on Korean speaking L2 learners of English production of passive structure. Similarly to us, they found that, regardless of proficiency level, their participants could be primed to use passive sentences in picture description. 
The very reliable boost to the production of indirect questions/requests, which tend to be underrepresented in Persian speakers' production of English fits the "inverse-preference effects" argument (Pickering \& Ferreira, 2008) according to which in any production contexts, structures that are less favored by participants/speakers seem to exhibit higher syntactic or structural priming. These effects might be because of the way speakers process prime structures, or the way they process target structures (see also Hartsuiker \& Kolk, 1998; Hartsuiker, Kolk, \& Huiskamp, 1999; Scheepers, 2003). The present results show that the same applies to priming studies in second language acquisition research.

The second research question of the study dealt with modality or interskill transfer, that is: Do the Persian speaking participants of the study who have been primed for the target structure transfer syntactic priming effects from one modality (speaking) to another (writing)? Particularly, transfer experiment was designed to address this question and the results showed that participants in the Experimental groups produced more target structure in their written production, a sign that the benefits gained during the priming session were available for this task as well. Nevertheless, the difference between Experimental and Control groups was significantly smaller in transfer experiment than in production experiment indicating that the transfer may not have been complete. Although the reason for this is not clear, one possibility is that, given that writing is a more demanding task, speaker may tend to employ the more frequent and easier structures to compensate.

\section{General conclusions}

Our data clearly show that priming can take place in a second/foreign language and that its effects are modality independent. Based on these findings several lines of enquiry suggest themselves. For example, one recurring theme in L2 research is the issue of cross-linguistic syntactic integration (De Bot, 1992; Ullman, 2001), that is, to what extent the two languages of a bilingual are separate. It should be possible to address this question using a syntactic priming paradigm by looking at whether bilinguals or second/foreign language learners can be primed by structures in one of their languages, and expect the target structure to be produced in the other language. If so, it would mean learners are making use of the same mechanisms to process the two languages (see Hartsuiker, Pickering, \& Veltkamp, 2004 for an investigation of the same issue among Spanish-English bilinguals). The role of proficiency in priming effects is yet another potentially interesting area of research in that it could help determine to what extent new structures can be "acquired" through priming. Still another promising and fruitful line of research using syntactic priming methodology can be the investigation of the role syntactic priming plays in the implicit learning of particular structures. This line of research will shed more light on mental processes involved in learning a second/foreign language.

Furthermore, syntactic priming can have a very practical use in the classroom. For example, in order to introduce grammar points, the teacher can prime the structure and then expect students to use that particular structure in their language production. This could be particularly helpful with structures that are less favored by the learners' first language. In Persian, for example, in addition to indirect speech, passives, tag questions, and causatives are among the less favored structures. These are, therefore, suitable for further investigation on syntactic priming and, possibly, for improvement of learning outcomes.

\section{Acknowledgements:}

We would like to thank Prof. Kathryn Bock, Prof. Holly Branigan, Prof. Martin Pickering, and Prof. Robert Hartsuiker for their helpful comments on different parts of this manuscript.

\section{References}

Allen, D. (1992). Oxford placement test. Oxford: Oxford University Press.

Bernolet, S., Hartsuiker, R.J., \& Pickering, M.J. (2007). Shared syntactic representations in bilinguals: Evidence for the role of word-order repetition. Journal of Experimental Psychology: Learning, Memory, and Cognition, 33, 931-949.

Bock, K. (1986). Syntactic persistence in language production. Cognitive Psychology, 18, 355-87.

Bock, K. \& Griffin, Z. M. (2000). The persistence of structural priming: Transient activation or implicit learning? Journal of Experimental Psychology: General, 1292, 177-92.

Branigan, H. (2007) Syntactic priming. Language and Linguistics Compass, 1, 1-16.

Branigan, H., Pickering, M. J., Liversedge, S. P., Stewart, A. J. \& Urbach, T. P. (1995). Syntactic priming: Investigating the mental representation of language. Journal of Psycholinguistic Research, 24, 489-506.

Chang, F., Dell, G. S., Bock, K. \& Griffin, Z. M. (2000). Structural priming as implicit learning: A comparison of models of sentence production. Journal of Psycholinguistic Research, 292, 217-29. 
De Bot, K. (1992). A bilingual production model: Levelt's 'Speaking' model adapted. Applied Linguistics, 41, 365-397.

Fisher, C. (2002). The role of abstract syntactic knowledge in language acquisition: A reply to Tomasello (2000). Cognition, 82, 259-278.

Garrod, S. \& Clark, A. (1993). The development of dialogue co-ordination skills in schoolchildren. Language and Cognitive Processes, 8, 101-126.

Gries, S. T. \& Wulff, S. (2005). Do foreign language learners also have constructions? Annual Review of Cognitive Linguistics, 3, 182-200.

Hartsuiker, R. J. \& Kolk, H. H. J. (1998). Syntactic persistence in Dutch. Language and Speech, 41, 143-184.

Hartsuiker, R. J., Kolk, H. H. J., \& Huiskamp, P. (1999). Priming word order in sentence production. Quarterly Journal of Experimental Psychology, 52A, 129-147.

Hartsuiker, R. J., Pickering, M. J., \& Veltkamp, E. (2004). Is syntax separate or shared between languages? Cross-linguistic syntactic priming in Spanish-English bilinguals. Psychological Science, 15, 409-414.

Kim, Y. \& McDonough, K. (2008). Learners' production of passives during syntactic priming activities. Applied Linguistics, 29/1, 149-154.

Levelt, W. J. M. \& Kelter, S. (1982). Surface form and memory in question answering. Cognitive Psychology, 14, 78-106.

Lotfi, A. R. (2003). Persian wh-riddles. In Boeckx, C. \& Grohmann, K. K., (Eds.), Multiple wh-fronting. Amsterdam: John Benjamins.

McDonough, K. (2006). Interaction and syntactic priming: English L2 speakers' production of dative constructions. Studies in Second Language Acquisition, 28, 179-207.

Pickering, M. J. \& Ferreira, V. S. (2008). Structural priming: A critical review. Psychological Review, 134 (3), 427-459.

Saffran, E. M. \& Martin, N. (1997). Effects of structural priming on sentence production in aphasics. Language and Cognitive Processes, 12, 877-882.

Scheepers, C. (2003). Syntactic priming of relative clause attachments: Persistence of structural configuration in sentence production. Cognition, 89, 179-205.

Schoonbaert, S., Hartsuiker, R.J., \& Pickering, M.J. (2007). The representation of lexical and syntactic information in bilinguals: Evidence from syntactic priming. Journal of Memory and Language, 56, 153-171.

Seger, C. A. (1994). Implicit learning. Psychological Bulletin, 115, 163-196.

Tomasello, M. (2000). Do young children have adult syntactic competence? Cognition, 74, 209-253.

Ullman, T. (2001). The neural basis of lexicon and grammar in first and second language: The declarative/procedural model. Bilingualism: Language and Cognition, 4, 105-122.

Weiner, E. J. \& Labov, W. (1983). Constraints on the agentless passive. Journal of Linguistics, 19, 29-58.

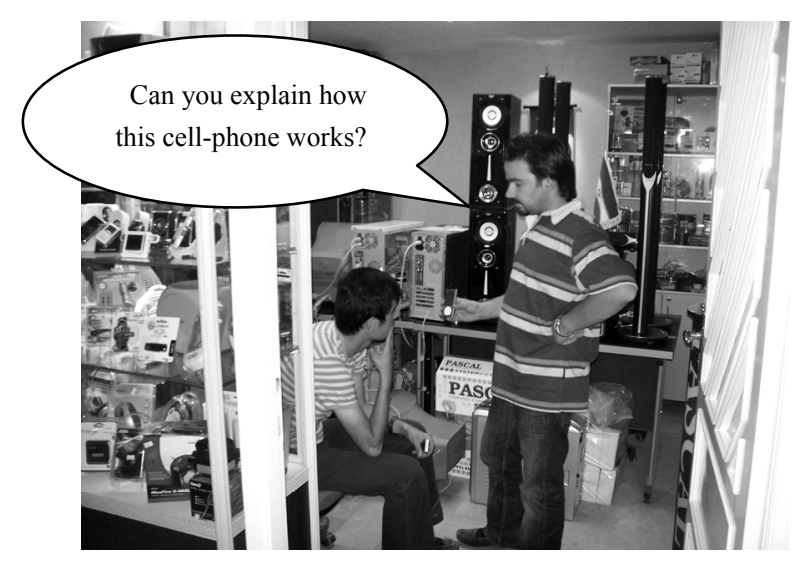


Figure 1. Experimental picture. In this picture a young man is showing a cell-phone to his friend and is asking about how the cell-phone works.

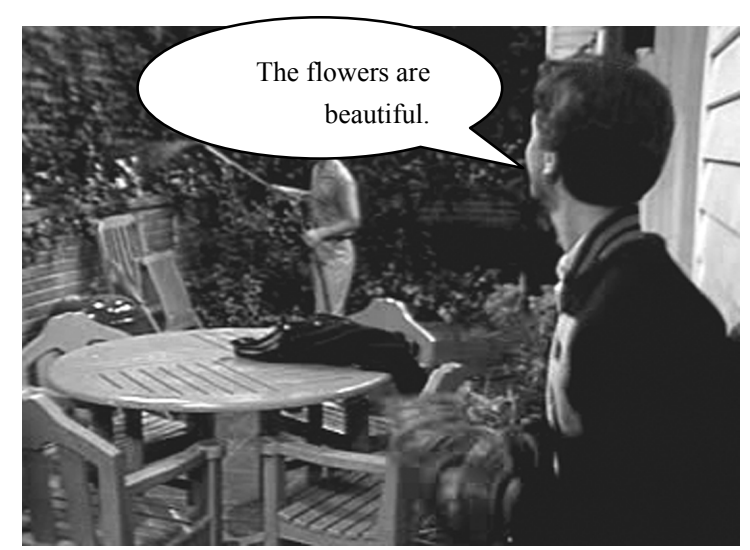

Figure 2. Filler picture. In this picture a young man is commenting on the flowers his friend is watering. 